\title{
Acute Synovitis
}

National Cancer Institute

\section{Source}

National Cancer Institute. Acute Synovitis. NCI Thesaurus. Code C97140.

An acute inflammation of a synovial membrane. It is associated with swelling and pain in the affected area. 